\title{
Current tidal power technologies and their suitability for applications in coastal and marine areas
}

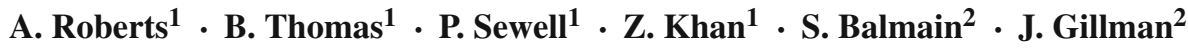

Received: 11 August 2015 / Accepted: 19 January 2016 / Published online: 18 March 2016

(C) The Author(s) 2016. This article is published with open access at Springerlink.com

\begin{abstract}
A considerable body of research is currently being performed to quantify available tidal energy resources and to develop efficient devices with which to harness them. This work is naturally focussed on maximising power generation from the most promising sites, and a review of the literature suggests that the potential for smaller scale, local tidal power generation from shallow near-shore sites has not yet been investigated. If such generation is feasible, it could have the potential to provide sustainable electricity for coastal homes and communities as part of a distributed generation strategy, and would benefit from easier installation and maintenance, lower cabling and infrastructure requirements and reduced capital costs when compared with larger scale projects. This article reviews tidal barrages and lagoons, tidal turbines, oscillating hydrofoils and tidal kites to assess their suitability for smaller scale electricity generation in the shallower waters of coastal areas at the design stage. This is achieved by discussing the power density, scalability, durability, maintainability, economic potential and environmental impacts of each concept. The discussion suggests that tidal kites and range devices are not well suited toward small-scale shallow water applications due to depth and size requirements, respectively. Cross-flow turbines appear to be the most suitable technology, as they have high power densities and a maximum size that is not constrained by water depth. Oscillating hydrofoils would also be appropriate, provided comparable levels of efficiency can be achieved.
\end{abstract}

A. Roberts

robertsa@bournemouth.ac.uk

1 Faculty of Science and Technology, Bournemouth University, Talbot Campus, Fern Barrow, Bournemouth, Poole, Dorset BH12 5BB, UK

2 The Balmain Environmental Trust, Rutter and Allhusen, 2 Longmead, Shaftesbury, Dorset SP7 8PL, UK
Keywords Tidal energy $\cdot$ Technology review $\cdot$ Small scale Shallow water

\section{List of symbols}

$\begin{array}{ll}A & \text { Device swept area }\left(\mathrm{m}^{2}\right) \\ A_{\mathrm{b}} & \text { Basin surface area }\left(\mathrm{m}^{2}\right) \\ A_{\mathrm{c}} & \text { Channel cross-sectional area }\left(\mathrm{m}^{2}\right) \\ B & \text { Channel blockage ration (dimensionless) } \\ b & \text { Hydrofoil blade span }(\mathrm{m}) \\ C_{\mathrm{p}} & \text { Turbine power coefficient (dimensionless) } \\ d & \text { Oscillating hydrofoil vertical motion extent } \\ & (\mathrm{m}) \\ E_{\mathrm{p}} & \text { Impounded water potential energy (J) } \\ g & \text { Acceleration due to gravity (taken as } 9.81 \\ & \left.\mathrm{~m} / \mathrm{s}^{2}\right)\left(\mathrm{m} / \mathrm{s}^{2}\right) \\ H & \text { Hydraulic head (m) } \\ P & \text { Power }(\mathrm{W}) \\ P_{\mathrm{d}} & \left.\text { Power density (W/m }{ }^{2}\right) \\ t & \text { Time (s) } \\ u_{\infty} & \text { Free-stream flow speed (m/s) } \\ E & \text { Efficiency boost due to blockage (dimension- } \\ & \text { less) } \\ \varepsilon & \text { Device efficiency (dimensionless) } \\ \rho & \text { Density (taken as } 1025 \mathrm{~kg} / \mathrm{m}^{3} \text { for salt water) } \\ & \left.\text { (kg/m }{ }^{3}\right)\end{array}$

\section{Introduction}

Nations across the globe are turning towards renewableslow-carbon energy sources that can be replenished on human timescales - to meet their energy and electricity needs. In Europe, the 2009 Renewables Directive set binding targets 
for all EU member states so that $20 \%$ of EU energy will come from renewable sources by 2020 (European Parliament and Council 2009). Meanwhile, the UK Government has committed to legally binding targets to reduce carbon emissions by $34 \%$ by 2020 and $80 \%$ by 2050, as set out in the 2008 Climate Change Act (HM Government 2008). To achieve these targets, it is predicted that $30 \%$ of UK electricity will need to be generated from renewable sources by 2020 (HM Government 2009), while the sector will need to be almost entirely carbon free by 2050 (HM Government 2011).

Of the many varieties of renewable energy, tidal power is one of the few that is almost perfectly predictable over long timescales (Denny 2009). As a marine renewable, tidal power deployments can be located in under-utilised locations (Fraenkel 2006), and so positioned out of sight and out of mind much more readily than large onshore devices, overcoming the so-called not in my backyard (NIMBY) problem that particularly affects wind power (Premalatha et al. 2014). Since the tides are out of phase around the coast, power is likely to be available at one tidal installation while there is slack water and no tidal power available in another part of the country (Fraenkel 2002). However, energy availability during neap tides is significantly less than that during spring tides, regardless of location.

There are two methods of generating electricity from the tides:

1. tidal range devices, which utilise the difference in water level between high and low tide;

2. tidal stream devices, which utilise the energy of flowing water in tidal currents to generate electricity directly.

Range devices are the most well-known form of tidal energy, thanks in no small part to the 220 MW Rance River Tidal Power Station in Brittany, France, which opened in 1966 and has been operating at full capacity since 1968 (Lebarbier 1975). However, tidal range schemes are currently receiving less research attention from government, industry and academia than the second method of tidal stream, which is perceived to benefit from lower installation costs and reduced environmental and ecological impacts (Fairley et al. 2013). Tidal stream is often considered to be analogous to wind energy, as in both methods energy is extracted from a moving fluid. However, while the wind industry has seemingly settled on three-bladed axial-flow turbines as the energy convertors of choice [due to a general acceptance that they are more efficient at larger scales (Howell et al. 2010)] there are currently many different technologies in development in the tidal stream sector. These include a multitude of different turbine designs, as well as more unusual concepts such as oscillating hydrofoils and tidal kites.

The bulk of current tidal energy research and development appears to be naturally focussed on developing larger scale schemes and devices to harness the greatest resources. As an example, Marine Current Turbines' (MCT) SeaGen device, arguably the most fully developed tidal stream turbine, is considered viable in 20-40-m-deep waters with peak spring tidal current velocities that are greater than $2.25 \mathrm{~m} / \mathrm{s}$ (Denny 2009), while proposed tidal range schemes typically enclose tens or hundreds of square kilometres of water Rourke et al. (2010a).

Many of the locations that meet these size and speed requirements, for instance Pentland Firth off the northeast coast of Scotland, are located in sparsely populated regions many kilometres from areas of peak electricity demand. A review of the literature suggests relatively little consideration has thus far been given to exploring the potential of smaller scale tidal power from more diverse locations that are closer to populated areas. For example, the 2025 UK tidal stream resource estimates provided by The Crown Estate (2012) were predicted assuming tidal turbine rotor diameters of $40 \mathrm{~m}$, operating in waters up to $60 \mathrm{~m}$ deep (The Crown Estate 2013).

There would be benefits to developing devices that could harness any potential resources in such locations. Aside from the obvious contribution to renewable energy targets (either through directly supplying renewable electricity to the grid or by reducing demand from other resources), efficiency savings in terms of reduced transmission losses would be made by generating power much closer to where it is needed. Additionally, connecting devices to the grid would be a more straightforward endeavour; near-shore sites would reduce the length of expensive undersea cabling required to transmit power back to land-a definite benefit given that the price of installing the cable can sometimes exceed the costs of the cable itself (de Alegría et al. 2009).

Small devices would by definition be cheaper to build and install than their larger counterparts (Bryden et al. 1998), and devices in shallow near-shore waters would also be more accessible, allowing easier installation and maintenance. These benefits could make small-scale tidal technology an appealing option for coastal communities as part of a distributed generation strategy, helping to overcome the variability of other renewables and fitting in to a wider context of sustainability and efficiency.

However, there are drawbacks that will need to be overcome if such sites are to be utilised. Chief amongst these is that these sites are likely to be less resource rich than those already under consideration. For example, in shallow waters the slower flow of the tidal current boundary layer will occupy a greater portion of the water depth, reducing the resource available to tidal stream devices (Polagye et al. 2010). Additionally shallow channels, which are already highly stressed due to bottom friction, produce proportionally less power and suffer a diminishing return as new devices are added due to increasing levels of drag (Vennell 2012). Lone devices may, therefore, be more cost-effective in such areas than larger 


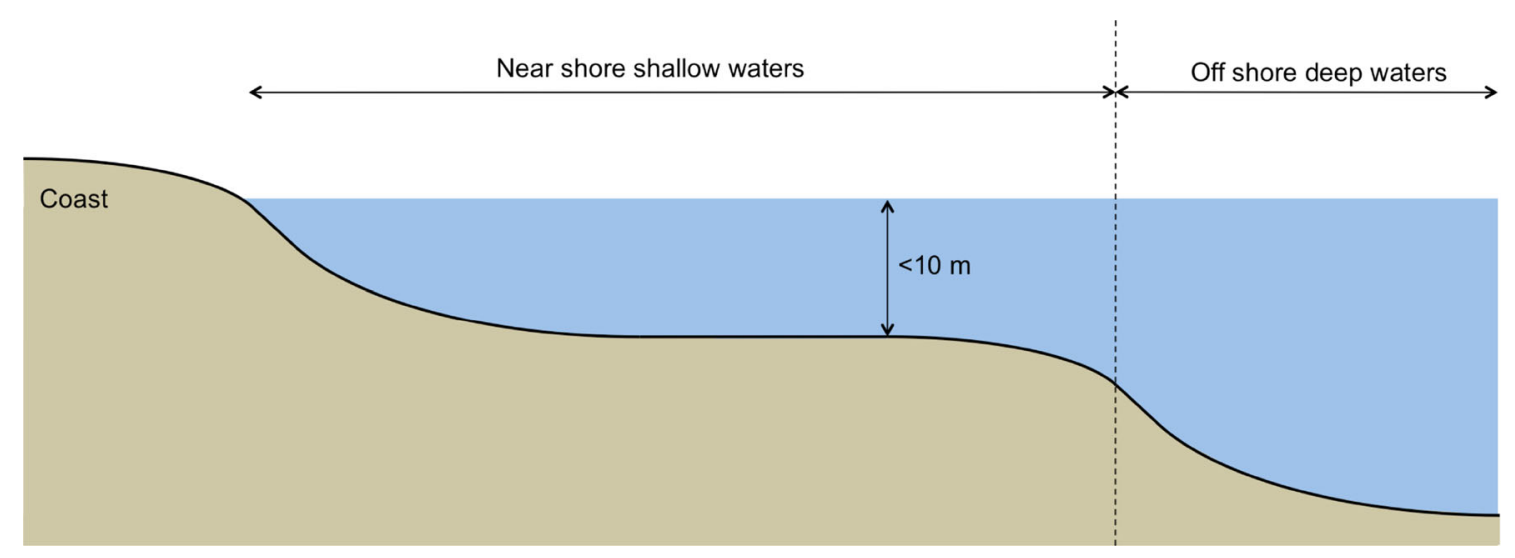

Fig. 1 Definition of shallow water location

arrays. Submerged devices in shallow waters will also be closer to the photic zone and hence subjected to a greater risk of bio-fouling; being closer to shore they are also likely to more readily impact highly complex and inter-dependent coastal ecosystems. Devices in shallow waters will also pose more of a navigational hazard to commercial and recreational marine traffic and, positioned close to shore, they may also impact other water users such as swimmers, and be more visible on land, potentially leading back to issues with NIMBYism.

The objectives of this article are to provide a general overview of the current major tidal technologies and to identify key criteria that will govern the effectiveness of a shallow water tidal energy deployment. In Sect. 3 we then discuss the potential performance of an isolated device from each discussed technology class for the case of an open coastline (i.e. where tidal currents are not naturally constricted by bathymetry) for near-shore waters of less than $10 \mathrm{~m}$ depth, as shown in Fig. 1. With careful consideration, the tidal resources of such areas could be utilised for the benefit of local communities that live within close proximity to them.

\section{Current tidal energy concepts}

\subsection{Tidal turbines}

Tidal turbines extract energy from a moving fluid; consequently they are somewhat analogous to wind turbines. Like wind turbines, most tidal turbines feature blades with aerofoil cross sections and operate according to the principles of aerodynamic lift, since this is more efficient than utilising aerodynamic drag (Hau and von Renouard 2013). However, there are major differences between the two technologies. The most immediately obvious are physical differences between the fluids; the density of seawater is approximately
$1025 \mathrm{~kg} / \mathrm{m}^{3}$, compared with around $1.25 \mathrm{~kg} / \mathrm{m}^{3}$ for $1 \mathrm{~atm}$. of air at room temperature.

Tidal currents are typically much slower than the wind, though the much greater density of water compensates for this in terms of power, allowing tidal stream devices to generate similar levels of output to wind turbines (Bahaj and Myers 2003). In contrast to wind power, there are no extreme flow speeds underwater that could potentially damage devices or force them to shut down (Blunden and Bahaj 2006); however, tidal stream devices must still be durable to withstand the greater loading forces generated by water. Further distinctions between the two technologies include differences in Reynolds number, the occurrence of cavitation and the bi-directionality of tidal currents (Batten et al. 2006); however, the most major differences are arguably the effects of blockage (Garrett and Cummins 2004) and the free surface (Whelan et al. 2009).

Tidal turbines can be broadly classified according to their design as either axial flow or cross flow, as illustrated in Fig. 2. Axial-flow turbines sweep through a circular area of water by rotating about an axis that is parallel to the flow direction. Cross-flow devices sweep through a rectangular area by rotating about an axis that is perpendicular to the flow, with water flowing across each blade twice.

The amount of power a turbine can extract from an unbounded fluid flow can be described mathematically using momentum theory (also known as actuator disc theory):

$P=\frac{1}{2} \rho A C_{\mathrm{p}} u_{\infty}^{3}$

This allows for a simple calculation of turbine power density (the power produced per $\mathrm{m}^{2}$ of total device area):

$P_{\mathrm{d}}=\frac{P}{A}=\frac{1}{2} \rho C_{\mathrm{p}} u_{\infty}^{3}$.

There is a theoretical limit to the amount of energy that can be extracted from an unbounded fluid. For a single actuator 
Fig. 2 Tidal turbine rotor types. Adapted from Entec UK Ltd (2007)

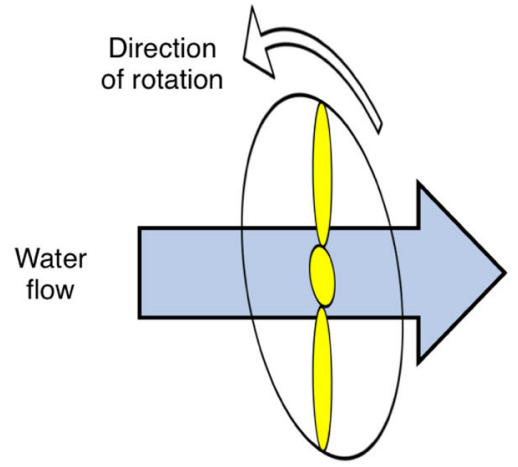

(a) Axial-flow turbine.

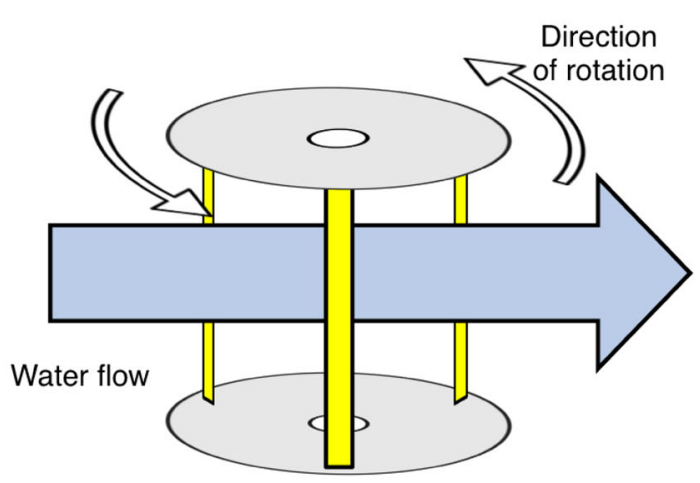

(b) Cross-flow turbine. disc (e.g. an axial-flow turbine) this limit is $59.3 \%(16 / 27)$ (Lanchester 1915; Betz 1966). The corresponding limit for a double actuator disc (e.g. a cross-flow turbine) has been shown to be slightly higher at $64.0 \%(16 / 25)$ (Newman 1983); a general limit of $66.6 \%$ (2/3) occurs for large number of discs (Newman 1986).

Although these theoretical limits generally hold true for wind turbines, for underwater turbines the assumption of an unbounded flow is rather unrealistic (Garrett and Cummins 2004). This is due to the proximity of the seabed and the sea surface, which act to constrain the flow (Bryden et al. 2007; Whelan et al. 2009). As a result, tidal turbines that are of significant size relative to their surroundings can exhibit $C_{\mathrm{p}}$ values that greatly exceed the Lanchester-Betz and Newman limits. As an example of this, the cross-flow turbine tested by McAdam et al. (2010) attained $C_{\mathrm{p}}$ values of up to $160 \%$.

This effect, known as blockage, is most noticeable in tidal channels where the flow is bounded not only by the seabed and surface, but also by the channel walls. As a result of this constriction, the power coefficient of an unducted axial turbine situated between two rigid surfaces (such as the walls of a tidal channel) is increased by a factor of $E$ (Garrett and Cummins 2007):

$E=(1-B)^{-2}$.

With the blockage ratio $B$ is defined as:

$B=\frac{A}{A_{\mathrm{c}}}$.

For the single small-scale device located along the open coastline that we consider in Sect. 3, the blockage ratio is likely to be small (since $A_{\mathrm{c}} \gg A$ ), meaning the efficiency increase $\left(1-A / A_{\mathrm{c}}\right)^{-2} \rightarrow 1$. As a result we do not consider blockage effects on power density here. Instead we simply note that tidal stream designs that are capable of being stretched horizontally through the water column will be able to take advantage of blockage effects, should a particular site feature regions of constrained flow (e.g. an underwater channel).

The power densities of ideal axial and cross-flow turbines in unbounded flows of up to $2 \mathrm{~m} / \mathrm{s}$ are plotted in Fig. 3, along with that of a theoretical $100 \%$ efficient turbine. Although cross-flow devices have a slightly higher ideal power density than axial turbines due to their slightly higher theoretical efficiency, practical device efficiency is heavily influenced by turbine design and performance. This is governed by a variety of factors such as rotor solidity (Consul et al. 2009), blade profile (Kadlec 1978) and Reynolds number (Roh and Kang 2013), blade pitch (Myers and Bahaj 2006; Kirke and Lazauskas 2008), blade shape (Baker 1983) and blade surface roughness (Howell et al. 2010; Walker et al. 2014).

\subsubsection{Axial-flow turbines}

Axial turbines currently appear to be the most popular tidal stream design; at the time of writing the European Marine Energy Centre (EMEC) lists 45 horizontal-axis turbines in commercial development. Of these, 15 are cross-flow turbines (since their axis of rotation is perpendicular to the flow) operating in a horizontal configuration; the remaining 30 are true axial-flow turbines (with an axis of rotation parallel to the flow direction) (European Marine Energy Centre 2014a).

The MCT SeaGen device, which has been undergoing testing in Strangford Lough, Northern Ireland, since 2008 (Bahaj 2011), is the first commercial-scale tidal turbine to generate electricity for the grid outside of a test centre. The device has a reported design life of 20 years (Douglas et al. 2008). A final version with 20-m 3-bladed rotors and a generating capacity of $2 \mathrm{MW}$ is currently in development.

The performance characteristics of the 3-bladed MCT device (MCT Ltd 2014) and four axial turbines: Atlantis Resource Corporation's AR1000 (European Marine Energy Centre 2014b); Bourne Energy's RiverStar (Bourne Energy 
Fig. 3 Ideal turbine power densities

Table 1 Performance characteristics of selected commercial axial-flow turbines

Table 2 Performance characteristics of academically developed axial-flow turbines

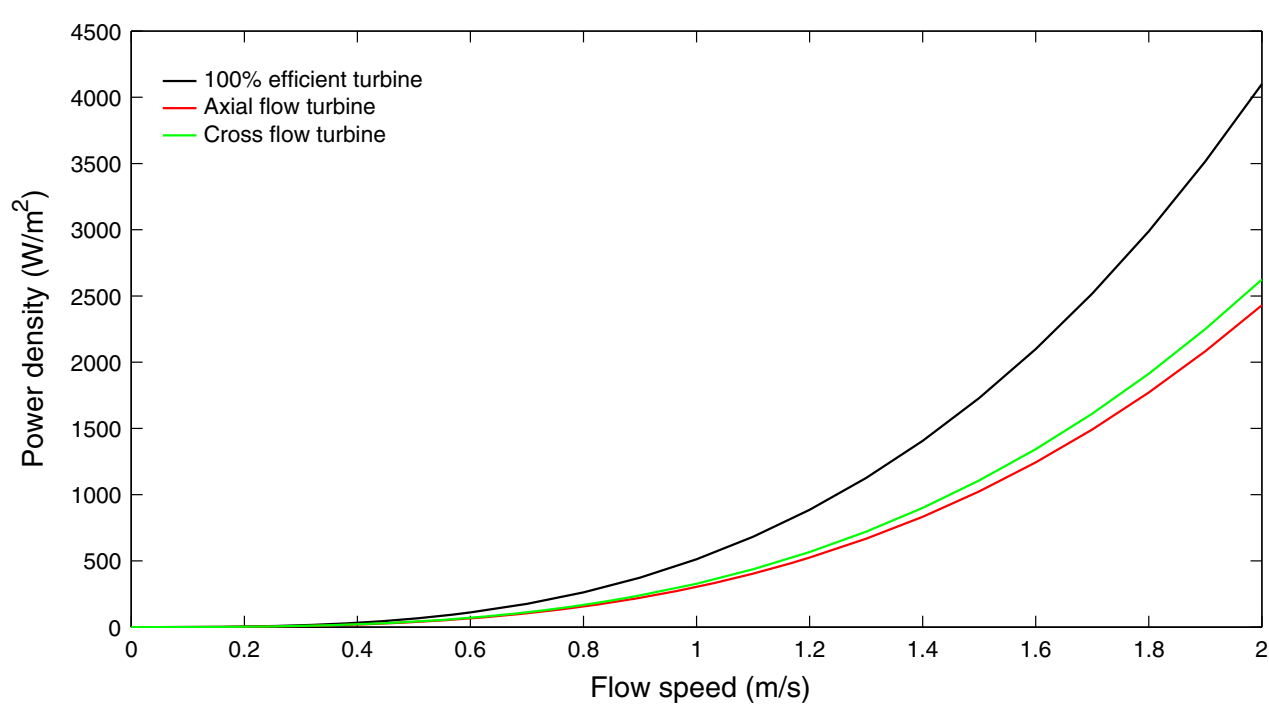

\begin{tabular}{llllll}
\hline $\begin{array}{l}\text { Developer } \\
\text { Device }\end{array}$ & $\begin{array}{l}\text { Atlantis } \\
\text { AR1000 }\end{array}$ & $\begin{array}{l}\text { Bourne } \\
\text { RiverStar }\end{array}$ & $\begin{array}{l}\text { MCT } \\
\text { SeaGen S }\end{array}$ & $\begin{array}{l}\text { Verdant } \\
\text { Gen5 }\end{array}$ & $\begin{array}{l}\text { Voith } \\
1 \text { MW test }\end{array}$ \\
\hline Rated power $(\mathrm{W})$ & $1.00 \times 10^{6}$ & $5.00 \times 10^{4}$ & $2.00 \times 10^{6}$ & $1.68 \times 10^{3}$ & $1 \times 10^{6}$ \\
Rated flow speed $(\mathrm{m} / \mathrm{s})$ & 2.65 & 2.05 & 2.40 & 2.59 & 2.90 \\
No. of rotors $(-)$ & 1 & 1 & 2 & 3 & 1 \\
Rotor diameter $(\mathrm{m})$ & 18.0 & 6.09 & 20.0 & 5.00 & 16.0 \\
Rotor swept area $\left(\mathrm{m}^{2}\right)$ & 254 & 29 & 314 & 20 & 201 \\
Rated $C_{\mathrm{p}}$ & 0.41 & 0.39 & 0.45 & 0.35 & 0.40 \\
\hline
\end{tabular}

\begin{tabular}{lllll}
\hline Study & $\begin{array}{l}\text { O’Doherty } \\
\text { et al. (2009) }\end{array}$ & Bahaj et al. (2008) & $\begin{array}{l}\text { Myers } \\
\text { and Bahaj } \\
(2006)\end{array}$ & $\begin{array}{l}\text { Coiro et al. } \\
(2006)\end{array}$ \\
\hline Maximum power (W) & 45 & $600^{\mathrm{a}}$ & 460 & 800 \\
Required flow speed (m/s) & 1.00 & 1.73 & 2.56 & 2.00 \\
No. of rotors (-) & 1 & 1 & 1 & 1 \\
Rotor diameter (m) & 0.50 & 0.80 & 0.40 & 0.80 \\
Rotor swept area $\left(\mathrm{m}^{2}\right)$ & 0.20 & 0.50 & 0.13 & 0.50 \\
Rated $C_{p}$ & 0.41 & 0.46 & $0.44^{*}$ & 0.40 \\
\hline
\end{tabular}

${ }^{\text {a }}$ Figure not reported in the literature but calculated using Eq. 1

2014); Verdant Power's Gen5 system (Polagye et al. 2010); and Voith Hydro's 1 MW test device (Voith Hydrop 2014); are outlined in Table 1.

These figures provide a possible indication of the potential of commercial axial-flow turbines; however, it is difficult to accurately verify performance data quoted by developers. Available experimental data on academically developed axial-flow turbines are presented in Table 2.

Comparing these tables shows that the commercially developed tested turbines appear to achieve similar levels of efficiency to those tested in the literature, despite the large differences in scale. The dependence of power output on flow speed and device size is also apparent.
Although tidal turbines are not predicted to have significant impacts on water levels, they have been predicted to noticeably impact water quality by reducing both upstream and downstream current velocities while increasing those along the side of an array (Ahmadian et al. 2012). This has implications for sediment transport, with a reduction in suspended sediment concentrations occurring upstream and downstream of an array while increasing significantly along its sides. In the region immediately around a tidal stream turbine the flow will be accelerated, which could lead to scouring of the seabed around the structure (Shields et al. 2011). Other models have also indicated that the extraction of energy from a tidal system will impact the sediment dynamics of a region, 
depending on the tidal asymmetry of the region (Neill et al. 2009). This can affect erosion and deposition a considerable distance from the point of energy extraction, and reduce the overall magnitude of bed-level change in comparison with non-extraction cases.

Marine energy devices such as tidal turbines can have many other impacts on their surrounding environment (Gill 2005). These include alteration of habitats for benthic organisms, noise pollution, the generation of electromagnetic fields and the striking of marine animals with rotor blades or other moving parts.

\subsubsection{Cross-flow turbines}

Cross-flow turbines (CFTs) rotate about an axis that is perpendicular to the flow direction. This axis can be positioned in either the vertical or horizontal plane relative to the flow, resulting in vertical-axis CFTs or horizontal-axis CFTs (also known as transverse horizontal-axis turbines (THATs)), as illustrated in Fig. 4.

Although less popular with wind developers, cross-flow turbines are not without their advantages. These are discussed by Eriksson et al. (2008) for vertical-axis wind turbines, and include omni-directionality, no need for pitch regulation or a gearbox, fewer moving parts, lower maintenance requirements, quieter operation and better performance in severe wind climates.

It is reasonable to suggest that many of these advantages also apply to cross-flow tidal turbines, which are the second most popular class of tidal stream technology with 26 different devices listed by EMEC at the time of writing (European Marine Energy Centre 2014a). There are various subcategories of cross-flow turbines, including straight-bladed Darrieus rotors, helical designs and devices designed to exploit channel blockage effects, all of which have differing levels of performance.

Performance data on commercially developed cross-flow turbines are less readily available than for axial turbines, perhaps indicating that the technology is currently at a lower technological readiness level (TRL). Table 3 details the performance characteristics of several academically developed cross-flow turbines.

The two lower efficiency devices (Shiono et al. 2000; Coiro et al. 2005) are traditional Darrieus rotor designs featuring straight blades. Although relatively easy and simple to build, one of the drawbacks of this design is that at low speeds, straight blades can suffer wildly varying angle of attack (Kirke and Lazauskas 2011). This makes fixed pitch straight-bladed devices liable to stall, reduces overall device performance, hampers their ability to self-start and imposes additional stresses on the device in the form of rapidly fluctuating torque pulsations.

In principle, it is possible to minimise these issues through the use of a pitch-control system (Kirke and Lazauskas 2011). Active pitch-control systems, where blade pitch is forced to follow a predetermined regime, are mechanically complex, however, the designs of passive pitch-control systems, where the forces acting on the blades control the pitch, are of dubious effectiveness. As a result of these problems, variablepitch Darrieus wind turbines have never reached commercial production (Kirke and Lazauskas 2011). Still, it does appear possible to make efficient hydrokinetic Darrieus rotors, as demonstrated by Kyozuka (2008), although it should be noted that the Reynolds number and blockage ratio that this design was tested do not appear to be defined.

The more efficient design of Yang and Shu (2012) features a helical rotor, which is claimed to have "all the advantages of a traditional Darrieus turbine without any of the disadvantages" (Gorban et al. 2001). Helical blades can even out

Fig. 4 Main variants of

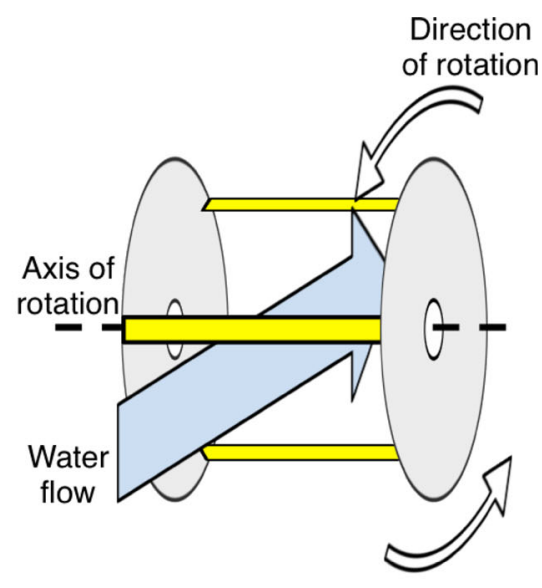

cross-flow turbines

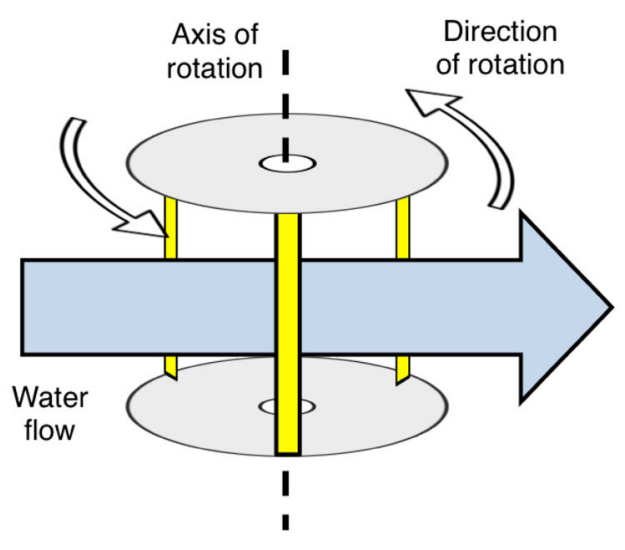

(a) Vertical-axis CFT. (b) Horizontal-axis CFT. 


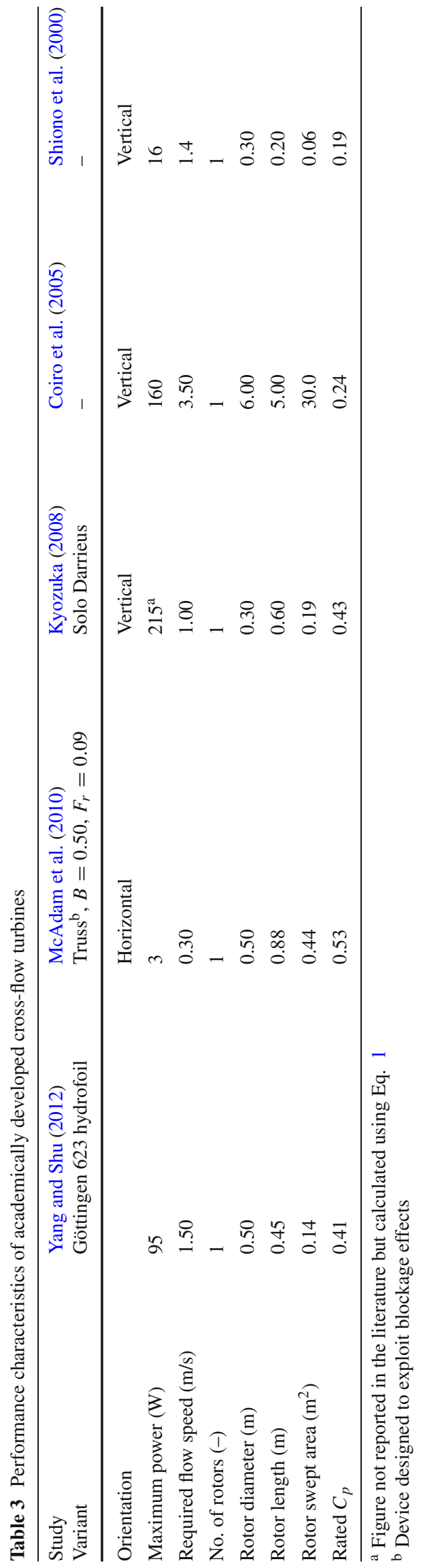

torque pulsations with changing azimuthal angle (Kirke and Lazauskas 2008), while their inclined nature means they also stall less abruptly, improving performance and starting torque (Baker 1983); however, these blades are more difficult and costly to construct. The most efficient device (McAdam et al. 2010) also features somewhat inclined blades; however, it is primarily designed to be large enough to take advantage of the blockage effects discussed in Sect. 2.1.

\subsubsection{Ducted turbines}

Ducts or diffusers can be added to both axial and crossflow tidal turbines to increase the mass flow rate over the rotor, allowing a given power output to be achieved from a smaller diameter turbine, as shown numerically by Shives and Crawford (2010). However, this definition of turbine diameter typically excludes the additional area of the duct itself. Although many ducted devices are claimed to be more efficient than their counterparts, a numerical study comparing devices of equal total size found that ducted turbines were less efficient overall than their unducted counterparts (Belloni 2013). The same study found that the performance of ducted and open-centre turbines was found to increase in yawed flow in contrast to unducted devices. Given the numerical nature of these studies, several assumptions were made, including simulating only a minimal turbine structure. Belloni (2013) primarily used an actuator disc model, which does not accurately model real turbine behaviour in comparison to a Reynolds-averaged Navier-Stokes blade element momentum (RANS-BEM) model, though performance trends remained consistent in both.

The additional structure of the duct and the stalled flow generated by diffusers will also increase the drag coefficient of a ducted turbine, which will in turn reduce the overall efficiency of ducted turbine arrays, particularly in regions of constrained flow (Shives and Crawford 2010). The effect of a diffuser on device performance is dependent upon its size and angle, with each having an optimum value (Gaden and Bibeau 2010).

EMEC currently lists eight different commercial developers working on ducted devices. Although there is little experimental data on ducted device performance available in the literature, details on two axial-flow commercial devices, a $200 \mathrm{~kW}$ OpenHydro demonstrator device (Polagye et al. 2010) and the small Clean Current CC035B (Clean Current Power Systems Inc 2012), are provided in Table 4 alongside a ducted cross-flow device, the $170 \mathrm{~kW}$ Davidson-Hill Venturi turbine (Tidal Energy Pty Ltd 2015). Two values of $C_{p}$ are provided, one calculated using the rotor diameter and a second assuming a total device diameter approximately 1.45 times that of the rotor. This figure is in line with the total/rotor area ratios for the devices reported in Table 2.2 of Belloni 
Table 4 Performance characteristics of selected commercial ducted turbines

\begin{tabular}{llll}
\hline $\begin{array}{l}\text { Developer } \\
\text { Device }\end{array}$ & $\begin{array}{l}\text { Clean current } \\
\text { CC035B }\end{array}$ & $\begin{array}{l}\text { Tidal Energy Pty Ltd } \\
\text { DHV 170 kW }\end{array}$ & $\begin{array}{l}\text { OpenHydro } \\
200 \mathrm{~kW} \text { demonstrator }\end{array}$ \\
\hline Rated power $(\mathrm{W})$ & $6.5 \times 10^{4}$ & $1.70 \times 10^{5}$ & $2.0 \times 10^{5}$ \\
Rated flow speed $(\mathrm{m} / \mathrm{s})$ & 3.00 & 3.00 & 2.50 \\
No. of rotors $(-)$ & 1 & 1 & 1 \\
Rotor diameter $(\mathrm{m})$ & 3.50 & 5 & 10.0 \\
Rotor swept area $\left(\mathrm{m}^{2}\right)$ & 10.0 & 19.6 & 79.0 \\
Rotor $C_{p}$ & 0.49 & 0.63 & 0.32 \\
Assumed total device area $\left(\mathrm{m}^{2}\right)$ & 20.0 & 41.2 & 158 \\
Total device $C_{p}$ & 0.23 & 0.29 & 0.16 \\
\hline
\end{tabular}

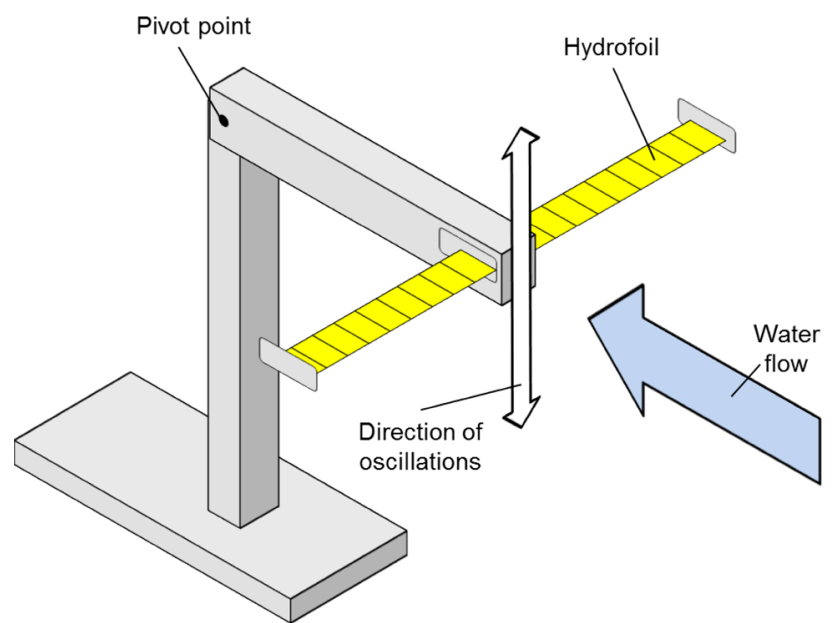

Fig. 5 Oscillating hydrofoil. Adapted from University of Strathclyde (2006)

(2013); however, this value can and will vary depending upon device design. It can be seen that the device $C_{p}$ values drop significantly if the additional area of a duct is considered.

\subsection{Oscillating hydrofoils}

An oscillating hydrofoil consists of a hydrofoil wing attached to a lever arm, as shown in Fig. 5. As a tidal current flows over the hydrofoil it generates lift, causing the lever to rise. At the peak of the rise the hydrofoil's angle of attack changes so that lift is generated on the underside, reversing the direction of motion. The resulting oscillations can be used to drive fluids in a hydraulic system to power a generator.

With this range of motion, the blades of an oscillating hydrofoil require a simpler geometry than those of an axial turbine. This is because the flow speed, and therefore angle of attack, over the blades will be the same along their entire length, meaning they do not require twisting like axial-flow turbine blades do. Consequently they are likely to be easier and cheaper to produce.
An oscillating hydrofoil extracts energy from the tidal current in a similar manner to a turbine (Kinsey et al. 2011). The only difference is the definition of swept area, which for a hydrofoil is the product of the extent of the vertical motion and the wingspan:

$P=\frac{1}{2} \rho u_{\infty}^{3} b d C_{\mathrm{p}}$

Since $A=b d$, power density is, therefore, the same as Eq. 2:

$P_{\mathrm{d}}=\frac{P}{A}=\frac{1}{2} \rho C_{\mathrm{p}} u_{\infty}^{3}$

Rourke et al. (2010b) mention that oscillating hydrofoil efficiency can be poor due to the time required to reverse the direction of oscillation; the Stingray device described in Table 5 was shelved due to poor performance. Pulse Tidal (2014) are currently developing another commercial oscillating hydrofoil device, although there appears to be little published performance data available at the time of writing. It is, therefore, difficult to draw any firm conclusions on the efficiency and power output of oscillating hydrofoils, as there is a lack of information available.

\subsection{Tidal kites}

A tidal kite consists of a relatively small turbine attached to a hydrofoil wing, with the entire arrangement tethered to the seabed. The motion of the tidal currents over the wing creates a lift force that pushes the kite forwards through the water. Through a combination of the tension in the tether and the use of a rudder, the tidal kite can be directed to "fly" along a given trajectory through the water column, as illustrated for the figure-of-eight trajectory of the Minesto Deep Green tidal kite in Fig. 6.

This movement increases the speed of the flow passing through an axial-flow turbine, allowing greater amounts of power to be generated from lower free-stream speeds using 
Table 5 Performance characteristics of oscillating hydrofoils

\begin{tabular}{lll}
\hline Device source & Kinsey et al. (2011) & $\begin{array}{l}\text { Stingray (The Engineer- } \\
\text { ing Business Ltd 2003, } \\
\text { 2005) }\end{array}$ \\
\hline Maximum power (W) & $2.00 \times 10^{3}$ & $8.53 \times 10^{3 \mathrm{a}}$ \\
Required flow speed (m/s) & 1.99 & 2.00 \\
Blade span (m) & 1.68 & 15.5 \\
Extent of vertical motion (m) & 0.61 & $12.6^{\mathrm{b}}$ \\
Swept area $\left(\mathrm{m}^{2}\right)$ & 1.02 & 195 \\
Power density $\left(\mathrm{W} / \mathrm{m}^{2}\right)$ & $1.96 \times 10^{3}$ & 43.7 \\
Rated $C_{p}$ & 0.40 & 0.12 \\
\hline
\end{tabular}

${ }^{a}$ Mean hydraulic power produced over 30-min operating period (The Engineering Business Ltd 2005)

b Calculated from arm length and operating angle reported in The Engineering Business Ltd (2003)

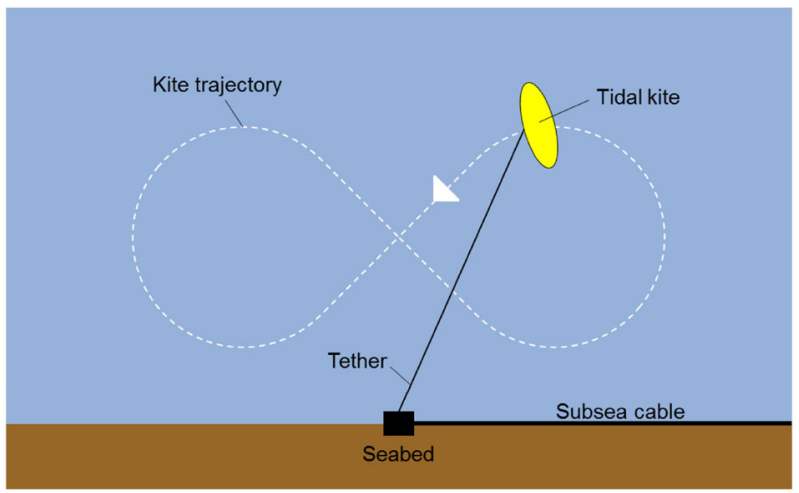

(a) Diagram showing the operation of the Deep Green tidal kite.

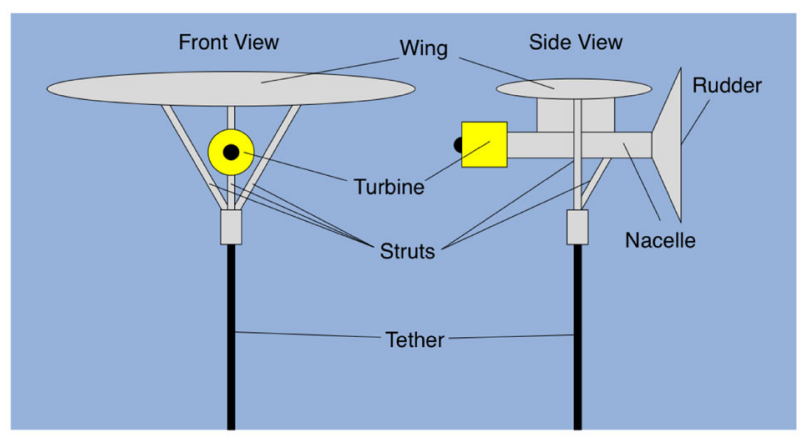

(b) Schematic of Deep Green.

Fig. 6 Operating method and schematic of Minesto's Deep Green tidal kite. Adapted from Minesto (2013)

a smaller turbine. The mechanical energy of the turbine is converted to electrical energy using a direct-drive generator attached to the kite, which is then transmitted through a cable in the tether to the seabed and then to the shore via a subsea cable. Table 6 summarises the specifications of several Deep Green devices.

The power coefficient estimates were calculated using Eq. 1, the rotor diameters and Minesto's claim that the device moves at a speed 10 times greater than the water current. For the calculated power densities, total device swept area was estimated as a semi-circle with the minimum tether length as its radius, resulting in the very low values shown. In practice, the swept area is likely to be much smaller than this. In water depths appropriate for the technology, tidal kites certainly appear capable of producing great amounts of power for the size of their rotors.

\subsection{Tidal range}

Tidal range devices make use of the difference in water level between high and low tide by impounding water within a basin before releasing it across turbines, as illustrated in Fig. 7. By closing sluice gates, water is trapped on one side of the device, creating a static head across it due to the movement of the tides. When the head is suitably large, the gates are opened and the excess water is directed across turbines for electricity generation.

Tidal range devices can use various generation schemes: ebb generation, flood generation and two-way generation (Xia et al. 2010a). These different schemes allow some flexibility in how the plant operates, depending upon the strength of the tide and grid requirements (Frau 1993).

- Ebb generation: power is generated when the flow is discharged across the turbines in the direction of the outgoing ebb tide, i.e. from the basin towards the sea. A full ebb generation cycle consists of four stages-filling, holding, generating and holding once again.

- Flood generation: essentially the mirror image of ebb generation, though generally less efficient due to the shape of the seabed. Since the volume of water in the upper half of the basin (utilised first by ebb generation) is greater than the volume in the lower half (filled first during flood generation), the water level difference across the barrage reduces more quickly.

- Two-way generation: an amalgamation of both ebb and flood schemes. Consequently the tidal range within the 
Table 6 Minesto Deep Green specifications

\begin{tabular}{lllll}
\hline Device & DG-8 & DG-10 & DG-12 & DG-14 \\
\hline Rated power (W) & $1.10 \times 10^{5}$ & $2.20 \times 10^{5}$ & $5.00 \times 10^{5}$ & $8.50 \times 10^{5}$ \\
Rated speed (m/s) & 1.30 & 1.40 & 1.60 & 1.73 \\
Rotor diameter (m) & 0.67 & 0.83 & 1.00 & 1.15 \\
Tether length (m) & $60-80$ & $75-100$ & $85-120$ & $110-140$ \\
Installation depth (m) & $50-65$ & $60-80$ & $75-100$ & $90-120$ \\
Wing span (m) & 8.00 & 10.0 & 12.0 & 14.0 \\
Weight (tonnes) & 2 & 4 & 7 & 11 \\
Devices $/ \mathrm{km}^{2}(-)$ & 50 & 30 & 25 & 16 \\
Power/m $\left(\mathrm{W} / \mathrm{m}^{2}\right)$ & 5.50 & 6.60 & 12.5 & 13.6 \\
Estimated swept area $\left(\mathrm{m}^{2}\right)$ & $5.70 \times 10^{3}$ & $8.84 \times 10^{3}$ & $1.14 \times 10^{4}$ & $1.90 \times 10^{4}$ \\
Estimated $\mathrm{P}_{d}\left(\mathrm{~W} / \mathrm{m}^{2}\right)$ & 19 & 24 & 44 & 45 \\
Estimated rotor $C_{p}(-)$ & 0.28 & 0.29 & 0.30 & 0.31 \\
\hline
\end{tabular}

Sourced from Minesto (2014)
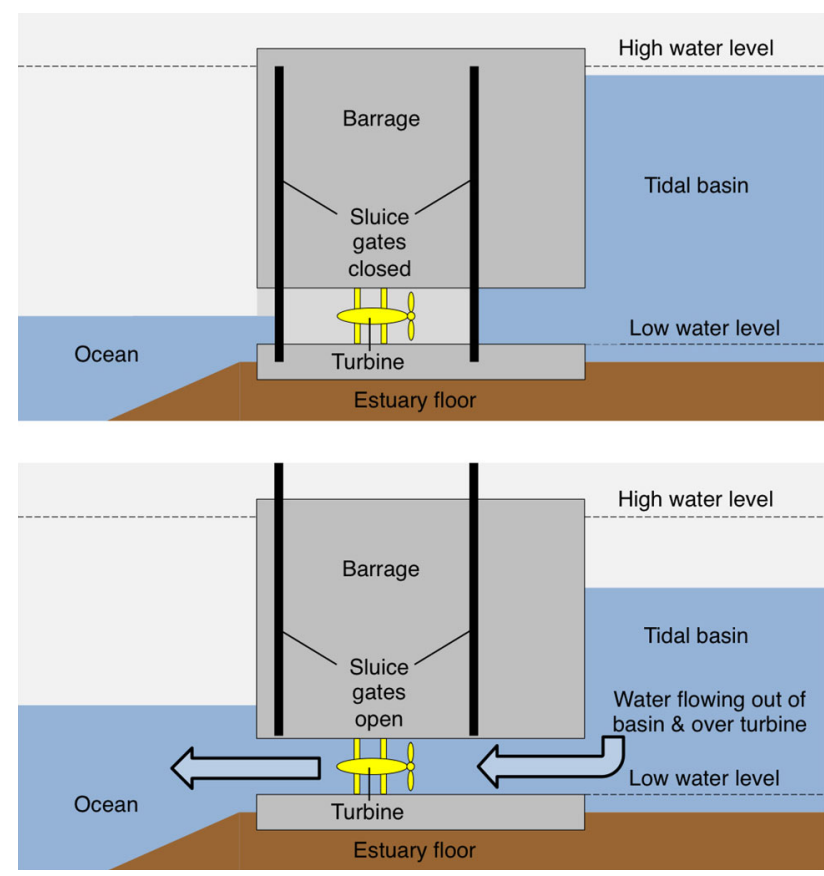

Fig. 7 Tidal barrage operation. Adapted from Wyre Tidal Energy (2014)

basin is closer to its natural range, which is thought to reduce environmental impacts in comparison to one-way generation.

By considering the volume of water impounded within the basin, a crude estimate of the potential energy (and subsequently power) available from a tidal range device can be obtained as follows (Lamb 1994):

$E_{p}=\frac{1}{2} A_{b} \rho g H^{2}$
The factor of $1 / 2$ arises due to the assumption of a linear reduction in hydraulic head as the basin empties (i.e. over half the tidal cycle). For a device utilising an ebb generation scheme, the average daily power generated by a range device is simply:

$P=\frac{E_{p}}{t} \varepsilon=\frac{A_{b} \rho g H^{2}}{2 t} \varepsilon$

where $t$ is the length of the tidal period in seconds. The power density in terms of power per unit of basin area can then be calculated as:

$P_{\mathrm{d}}=\frac{P}{A_{b}}=\frac{\rho g H^{2}}{2 t} \varepsilon$

The maximum power density values for four theoretical range schemes of different efficiencies, calculated using Eq. 9, are shown in Fig. 8 for tidal ranges between 0 and $20 \mathrm{~m}$.

It can be seen from this simple analysis that barrages and lagoon devices only produce a small amount of power for their surface area. For the maximum calculated $20 \mathrm{~m}$ tidal range, the available power density for a $100 \%$ efficient range device is approximately $45 \mathrm{~W} / \mathrm{m}^{2}$, while for the $16 \mathrm{~m}$ tidal range found in Canada's Bay of Fundy [which has the highest tides in the world (Archer and Hubbard 2003)] the power density is approximately $30 \mathrm{~W} / \mathrm{m}^{2}$.

There are relatively few locations in the world that have tidal ranges approaching this value, however, meaning range devices are unlikely to reach this figure in all but a handful of places. Tidal range projects are also typically characterised by low values of $\varepsilon$ (Xia et al. 2012), with values typically ranging from 20 to $40 \%$ and an average of $33 \%$ often used in theoretical energy output estimations. At these efficiencies, the power density of a range scheme is clearly going to be lower. 
Fig. 8 Theoretical power density for a barrage or lagoon for tidal ranges of $0-20 \mathrm{~m}$

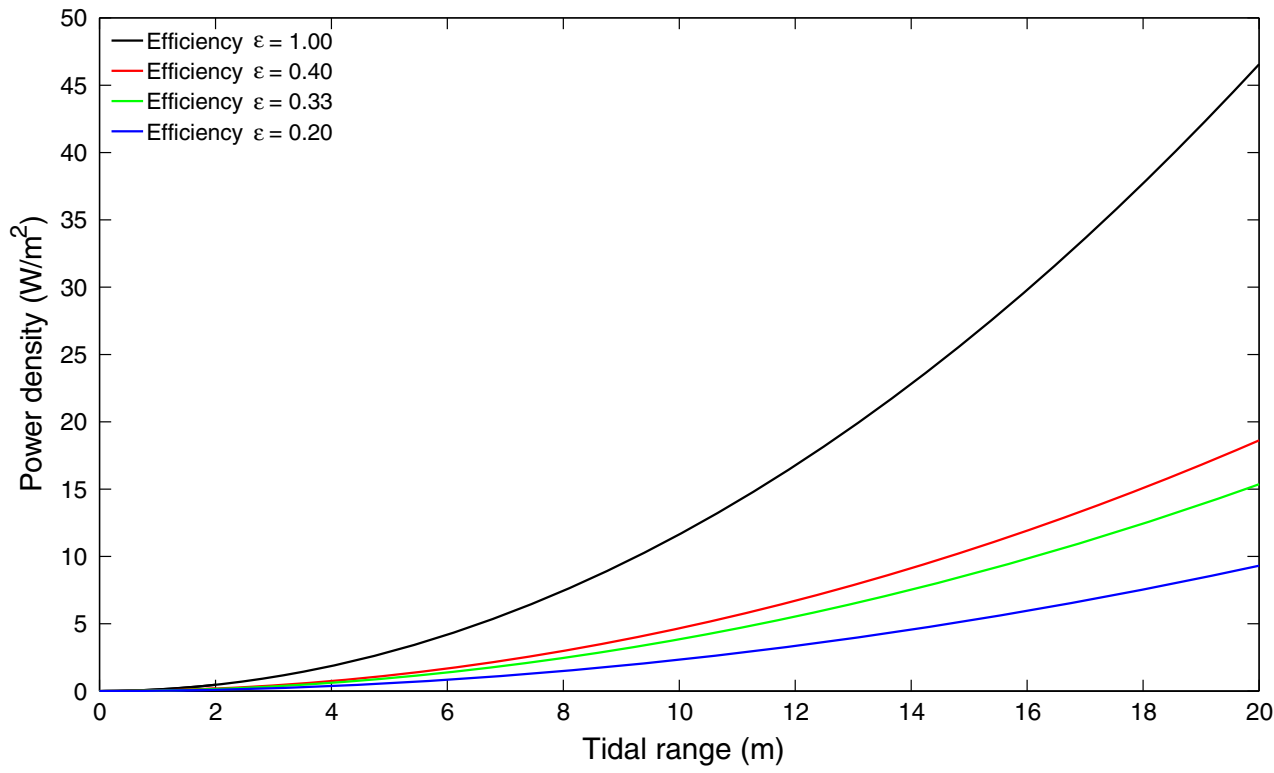

Table 7 Current operational barrages

\begin{tabular}{llllll}
\hline Barrage & Inauguration date & Mean tidal range $(\mathrm{m})$ & Basin area $\left(\mathrm{km}^{2}\right)$ & Capacity (MW) & Source \\
\hline La Rance, France & 1966 & 7.9 & 43 & 240 & Frau (1993) \\
Sihwa Lake, South Korea & 2011 & 7.8 & 23 & 254 & Kim et al. (2012) \\
Annapolis Royal, Canada & 1985 & 6.4 & 6 & 20 & Frau (1993) \\
Jiangxia, China & $1980 / 1986$ & 5.0 & 2 & 3.2 & Frau (1993) \\
Kislaya Guba, Russia & 1968 & 2.4 & 2 & 0.4 & Frau (1993) \\
\hline
\end{tabular}

As stated above, however, the values provided by Eqs. 7-9 are only a crude estimate. For a specific location, integrating over the tidal curve, rather than averaging, will provide a more realistic estimate of power. Given that the shape of the basin and turbine positioning can also affect range scheme performance, numerical models, such as those of Xia et al. (2010b) provide an even more accurate method of assessing potential power output. It is also worthwhile to consider the power output of currently operational tidal range devices, which are presented in Table 7.

The economics of a range scheme scale according to the amount of water in a basin between mean high and low tide, which is known as the volume of the tidal prism (Frid et al. 2012). As a result, optimal tidal range structures are situated in estuaries with high tidal ranges, and feature large basins for water impoundment (Kadiri et al. 2012).

A particular advantage of tidal range structures is their very long lifespans; for example, the design lifetime of the proposed Severn Barrage is 120 years, with turbine replacement occurring every 40 years (Kelly et al. 2012). Range structures have such long operational lifetimes due to the fact that the turbines are enclosed within a sturdy concrete structure and are consequently less exposed to the marine environment, with relatively easy access provided for maintenance work.

\subsubsection{Tidal barrages}

Tidal barrages are long structures built across bays or estuaries, making use of the surrounding land to create a basin in which water can be impounded.

Barrages are mature and reliable; however, they do come with significant capital and environmental costs that can be difficult to overcome (Blunden and Bahaj 2006). This is evidenced by the fact that there are only five tidal barrages currently in operation globally, despite there being several sites across the world considered suitable for development (Charlier 2007)

The largest example of a barrage is the Sihwa Lake Tidal Power Station in South Korea, which is rated at 254 MW and makes use of a seawall that was originally constructed in 1994 for flood defence (Bae et al. 2010). A list of operation tidal barrages, such as the Rance River Barrage shown in Fig. 9, provided in Table 7.

In regions of high tidal range, such as the Severn Estuary in the UK, large-scale range schemes would be capable of producing colossal amounts of power. For example, the proposed Cardiff-Weston barrage in the Severn Estuary, UK, would have an installed capacity of $8.64 \mathrm{GW}$ and provide an estimated $17 \mathrm{TWh}$ of electrical energy per year (Xia et al. 2010a). This power capacity is significantly greater than the 


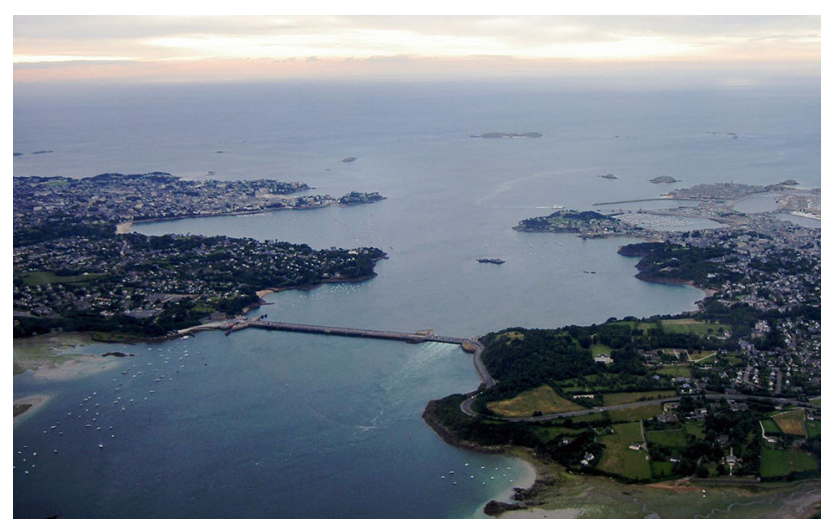

Fig. 9 The Rance River Barrage, Brittany, France. Sourced from wikipedia.org (2015)

maximum of $154 \mathrm{MW}$ predicted by Ahmadian and Falconer (2012) for tidal stream turbine arrays in that location. Indeed, the predicted 17 TWh of energy per year is greater even than the estimated 12.7 TWh/year resource available in the entire Pentland Firth, arguably the UK's top site for tidal stream power (Sustainable Development Commision 2007).

Such schemes can also have significant environmental impacts, both positive and negative. For example, Kirby and Shaw (2005) argue that a Severn barrage would reduce the strength of the tidal currents and thus reduce the suspended sediment load while providing greater bed stability, encouraging the colonisation of an otherwise highly suppressed ecosystem. Through a numerical study, Ahmadian et al. (2010) confirmed that suspended sediment levels in peak spring tide conditions would reduce from 1200 to $200 \mathrm{mg} / \mathrm{l}$ upstream of a Severn barrage. More generally, the change in suspended sediment loads is related to the local geology of the estuary bed (Xia et al. 2010b); consequently it is difficult to say whether this reduction would occur in all locations. Barrages and lagoons are also likely to increase sediment deposition in certain areas, the location and magnitude of which will depend upon specific design and the prevailing source of the sediment (Kadiri et al. 2012).

Tidal barrages have also been found to impact on surrounding water levels. For example, Xia et al. (2010c) predicted that maximum water levels upstream of a Severn barrage would decrease by $0.5-1.5 \mathrm{~m}$, reducing the risk of flooding along the estuary. Barrages, therefore, have additional use as flood defences, particularly in the context of climate change and rising sea levels (Ahmadian et al. 2014). This may be a huge benefit for certain locations, given that it will also prevent the need to spend money on conventional flood defences (Department of Energy and Climate Change 2010). In a similar vein they may also be used as bridges across bodies of water, leading to regeneration opportunities, as is the case at La Rance in France.

For ebb generation schemes, the reduction of water levels caused by a barrage also has negative connotations, particu- larly in terms of habitat loss. For example, Zhou et al. (2014) predicted through numerical modelling that the siting of an ebb-only barrage across the Severn Estuary between Cardiff and Weston-Super-Mare would result in the loss of $80.5 \mathrm{~km}^{2}$ of intertidal habitats. Zhou et al. (2014) also predicted that salinity levels would be reduced by up to 5 parts per thousand at high water upstream of the device. This would reduce dissolved metal and nutrient concentrations in the water column (Kadiri et al. 2012), and would also impact on dissolved oxygen concentrations, again impacting on habitats within the area.

Local wave climate may also be affected, for example, (Fairley et al. 2014) found that the construction of a Severn barrage would increase net downstream wave heights over a tidal cycle by almost $20 \%$ compared to pre-barrage conditions, which could have implications for coastal erosion and sediment transport.

These impacts on water levels and habitats can be reduced through the use of two-way generation, which allows the tidal range of the basin to remain closer to its natural cycle. The impacts may not be completely mitigated however; the numerical model of Xia et al. (2010c) indicated that water levels upstream of a two-way barrage are still reduced, which will lead to habitat loss.

Other methods for minimising the environmental impacts of barrages can be seen in the Evans Engineering REEF system (Evans Engineering and Power Company 2011), which maintains a small but constant head difference rather than delaying the tides to generate a larger head. This is also thought to reduce the effect on the tidal range of the basin, in turn reducing impacts on intertidal habitats. The proposed scheme also features low-head, low-speed turbines, with a small number of widely spaced blades, to assist the passage of migratory fish. The two-way Hafren barrage scheme for the Severn Estuary, featuring 1026 Very Low Head bidirectional turbines, has also been proposed as a way of mitigating impacts on wildlife, with up to $60 \%$ less habitat loss in comparison to an ebb-only scheme. However, the case for the Hafren barrage is currently unproven (House of Commons Energy 2013). In addition to a failure to demonstrate value for money for consumers, this is still partly due to environmental concerns. These include the loss of some intertidal habitat due to a reduction in tidal range and apparent contradictions regarding impacts on flooding. These issues highlight the lack of empirical data surrounding the environmental impacts of tidal power in general, and demonstrate the need for further research before such impacts can be assessed with certainty.

\subsubsection{Tidal lagoons}

A tidal lagoon is similar to a barrage; however, instead of building a single structure across the width of a bay or estuary 
and using surrounding land to form the basin walls, a tidal lagoon consists of an entirely man-made basin with turbines embedded within the constructed walls. Consequently, since a larger structure is required to create a basin of comparable area to that of a barrage, tidal lagoons require higher capital expenditure than barrages of comparable power (Baker et al. 2006; Entec UK Ltd 2007).

Without blocking off an entire estuary or bay, the impacts of a lagoon on water flow, sediment transport, fish migration and shipping may be comparatively less than those of barrages outside the basin area and on the region as a whole (Kadiri et al. 2012). For example, the construction of a tidal lagoon on the Welsh coast of the Severn Estuary has been predicted to have little impact on the hydrodynamics of the region overall (Xia et al. 2010b), though the hydrodynamics within the lagoon itself can still be changed dramatically. Additionally, impacts in the area immediately surrounding a lagoon, particularly on sediment transport, may be more significant than for barrages. For example, the proposed Swansea Bay Tidal Lagoon is predicted to interrupt the transport of sand, creating a build-up of material along the outside of the structure's eastern wall (Tidal Lagoon Swansea Bay plc 2015). Consequently a monitoring plan is being developed to implement measures such as beach nourishment and dredging where necessary.

In the same region, it has also been predicted that coastally attached lagoons will cause a smaller reduction on upstream water levels in comparison to barrages (Kadiri et al. 2012). While this may be of benefit in terms of minimising habitat loss, it also indicates that lagoons are likely to not be as effective at reducing the risk of flooding. Even so, studies of proposed tidal lagoons off the coast of North Wales have shown that coastally attached impoundments can offer some level of reduced flood risk, by reducing peak tidal levels and reducing wave heights (Ahmadian et al. 2010).

Inside the basin, sediment deposition is likely to occur, and periodic dredging may be required to preserve energy yield (Department of Energy and Climate Change 2010). This is due to the generation of strong recirculating currents within the impoundment area as a result of turbines being located in only part of the wall, inducing tidal eddies or large vortices (Ahmadian et al. 2010). Spreading the turbines around the perimeter of the device, as is done along the length of barrages, can reduce the likelihood of such eddies, however, for lagoons this is likely to reduce their commercial viability.

At the time of writing no tidal lagoons have been built. However, negotiations for the construction of a tidal lagoon in Swansea Bay, which could produce $500 \mathrm{GWh} /$ year of electricity, are underway (HM Government 2015). Figure 10 provides an image of the proposed lagoon area.

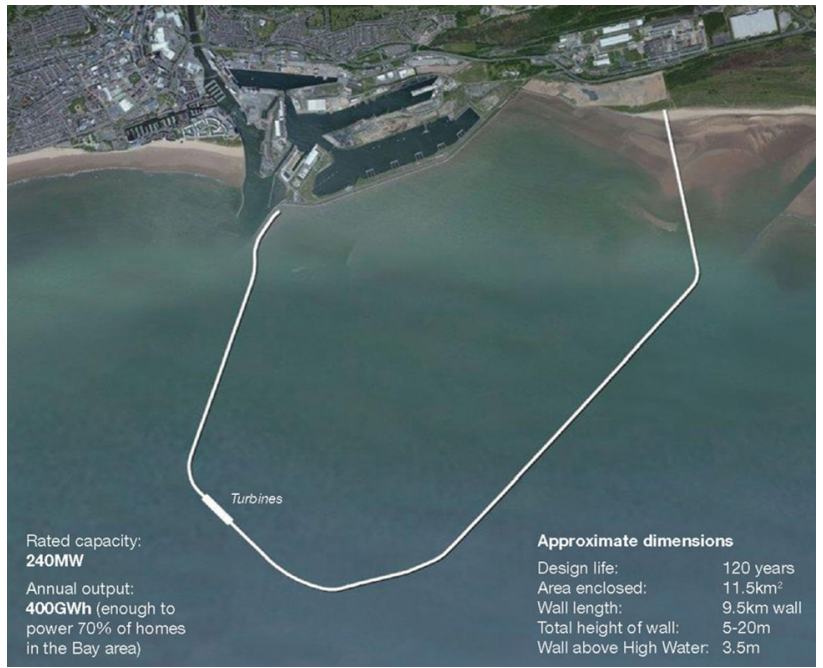

Fig. 10 Map of the proposed Swansea tidal lagoon. Sourced from Tidal Lagoon Swansea Bay plc (2015)

\section{Technology comparison}

\subsection{Methodology}

To assess the suitability of the discussed technologies for small-scale shallow water applications, we identified six criteria that will govern the success of tidal energy deployments from the literature. The majority of these come from Bahaj and Myers (2003), who describe the fundamentals applicable to tidal energy deployments.

- Power density: a measure of how much power a concept can generate for its size. At this stage, only hydrodynamic efficiency and power are considered, i.e. the effects of gearboxes and electrical generators on efficiency and output are ignored.

- Scalability: the ability to increase the size of a technology given the constraints of a shallow water site. Even at small scales, the ability to make a device large enough to produce a desired power output will be important.

- Durability: the ability of a concept to survive in the harsh marine environment, where it will have to overcome corrosion, debris impacts, high loading forces and bio-fouling among other issues (Bahaj and Myers 2003). Some concepts will be more susceptible to these problems than others, depending upon their complexity, the number of moving parts they have and how exposed these parts are.

- Maintainability: the ease with which a concept can be maintained and repaired. Measures can be undertaken during the design stage to reduce and simplify maintenance (Bahaj and Myers 2003), including the use 
of good-quality lubricants, seals, and strong materials, incorporating all the moving parts of the device into one specific feature and an ability to raise the device out of the water.

- Economic potential: for a concept to be viable it must generate electricity at a competitive cost. However, given the many variables involved it is difficult to quantify the economic potential of each concept precisely; therefore, a more qualitative assessment based on the complexity, scalability and power density of each device is used.

- Environmental impacts: many coastal regions are ecologically diverse areas, and are used for a wide number of commercial and recreational activities. Consequently, it is vital to consider the magnitude of the impacts each concept has on its surroundings, given that even relatively small interventions can cause significant impacts.

We perform a design-stage examination of the performance of each tidal technology class by comparing their performance against that of a reference concept, in this case the axial-flow tidal stream turbine. Given the site-specific nature of tidal power and the absence of large amounts of data for many of the technologies, we limit our evaluation to discussion only, using the particular benefits and drawbacks of each technology to highlight those most suited to small-scale shallow water generation.

\subsection{Technology comparison}

\subsubsection{Power density}

Given the dependence of power output on device efficiency and site bathymetry, along with either flow speed or tidal range, it is difficult to directly compare the power density of technologies in the absence of specific site data. However, some broad points can be drawn from the data presented in Sect. 2.

As shown in Fig. 3, axial-flow turbines are theoretically capable of generating over $1 \mathrm{~kW} / \mathrm{m}^{2}$ in unbounded flows greater than $1.5 \mathrm{~m} / \mathrm{s}$, while theoretical cross-flow devices should be capable of producing slightly more power for their size in those same flows. Given that the reported efficiencies of three of the experimental cross-flow devices presented in Table 3 are similar or greater than those of the axial-flow devices in Tables 1 and 2, it seems reasonable to suggest that cross-flow devices can produce more power for their size than axial turbines, which will be of benefit in smallscale deployments, particularly in shallow waters. Although oscillating hydrofoils may have issues with efficiency if the Stingray device is indicative of their performance, the device tested by Kinsey et al. (2011) suggests their efficiencies can also be comparable to those of unducted turbines. This means they should also be capable of producing large amounts of power for their size.

Other tidal stream concepts do not appear to compare so favourably however. Ducted turbines, both axial and cross flow, are capable of producing a given amount of power from a smaller rotor than an unducted device, while the duct also assists power generation in yawed flow. Once the extra area of the duct is taken into account, however, the power produced by the total device is likely to be comparatively less than that of an unducted turbine. Tidal kites, which are again capable of producing great power for the size of their rotors, presently require large installation depths, effectively making them unfeasible in shallow waters.

The power density of tidal range devices, though appearing to be much lower than that of axial-flow turbines, is defined differently, in that it is the power per unit of basin area, rather than power per unit of frontal area. Consequently, provided a location has a large enough tidal range to create sufficient head for generation, barrages and lagoons will be perfectly capable of operating in shallow waters. Their low power density in terms of surface area does, however, mean that their basins will likely need to be at least hundreds of square metres to generate comparable levels of power. This would somewhat defeat the purpose of a small-scale device, since the amount of investment and materials required to create such a basin, particularly for a lagoon, will be significantly higher than that required to install a turbine of similar output (assuming the resources are there for both technologies).

\subsubsection{Scalability}

In shallow waters, the maximum size of an axial-flow turbine will be constrained by water depth due to the circular swept area of its rotor, which would limit maximum power output. For both vertical and horizontal-axis cross-flow turbines, however, size would not be limited due to their rectangular area; consequently they could be scaled up to reach a specified output. Oscillating hydrofoils also benefit from a rectangular swept area, and consequently could be scaled according to a specific demand as well.

For a ducted device, the extra space required by the duct itself would limit the overall scalability in comparison to an unducted turbine. Tidal kites would be even more limited in shallow waters, given that they require long tether lengths so they can sail through their figure-of-eight motion.

Given that their power output is dependant on the difference in water level between high and low tide but independent of actual water depth, the maximum size of a tidal range device would not be constrained by water depth. While a barrage would require a natural basin, such as a bay or estuary, to serve as an impoundment area, in theory lagoons can be constructed on or off any open coastline with a tidal range large enough to provide a sufficient head. This would be a 
definite advantage, in terms of reaching a desired power output.

\subsubsection{Durability}

\section{Axial-flow turbines}

The rotor blades of unducted axial-flow turbines are completely exposed to the marine environment, making them susceptible to damage and bio-fouling, which would be an issue in shallow waters due to the proximity of the photic zone. To produce power from both flood and ebb tides, axialflow turbines also require some sort of yawing mechanism to ensure they are facing the prevailing current direction.

Vertical cross-flow turbines are omni-directional while horizontal designs are bi-directional, negating the need for yawing mechanisms and so reducing complexity in comparison to axial turbines. Blade tips will also be less exposed than those of an axial turbine, although the blades will be susceptible to damage and bio-fouling. Torque pulsation can be an issue for straight-bladed Darrieus rotor designs, which require pitch-control mechanisms to limit the blade angle of attack and minimise stalling at low speeds. The use of helical blades can also prevent this problem, however, without increasing mechanical complexity.

A duct would provide some protection for the blades of both axial and cross-flow turbines against debris and biofouling, while the need for a smaller rotor to produce a given amount of power would also help improve durability. In contrast, the fully exposed blades of an oscillating hydrofoil are likely to suffer similar effects as those of unducted axialflow turbines. Given their oscillatory motion, fatigue may also be more of an issue for hydrofoils than it is for axialflow turbines, and such problems would be exacerbated with increasing blade length. The additional complexity of multiple moving parts means tidal kites may also suffer in terms of durability.

Both barrages and lagoons will be much more durable than axial-flow turbines, given that their turbines are less exposed to the marine environment. This can be seen in a comparison of the lifespans of the structures: while the MCT SeaGen has a design life of 20 years, a proposed Severn Barrage has a design life of 120 years (with the turbines themselves needing replacing at 40-year intervals).

\subsubsection{Maintainability}

Maintenance of axial-flow turbines would be challenging, since all moving parts, including the generator, tend to be located underwater. This can be overcome in design, through the use of stronger materials, a geared transmission system to position the generator above the surface and lifting rotors such as those on the MCT SeaGen device.
A vertically oriented cross-flow device would permit the generator to be located above the water line without the need for anything more complex than a drive shaft, which would permit easier maintenance. Axial-flow turbines and horizontal CFTs require a more complex transmission system to achieve this; however, it is eminently possible through the use of gearing or universal joints. In all cases, however, maintenance of the turbine itself will be challenging, given that it is located underwater. For ducted turbines this will be complicated further due to the duct potentially restricting access to certain parts, otherwise their maintenance needs would be broadly similar to those of unducted turbines.

The maintenance needs of oscillating hydrofoils will be different to those of turbines, given that they have a different power take off mechanism. The presence of additional hydraulic fluids underwater and the potential for leaks into the environment may make maintenance more difficult. As with turbines, however, the generator itself could be located above the surface for easy access. Meanwhile tidal kites would be relatively easy to maintain in comparison to turbines, since the kite itself can be detached from the tether and floated to the surface for repair work.

The turbines of a barrage or lagoon would be relatively easy to reach for maintenance work, however, depending on the site and generation scheme employed, dredging of the basin may be required to counter sedimentation and preserve energy yield.

\subsubsection{Economic potential}

Despite producing good amounts of power for the size of their rotors, the limitations on the maximum size of axial-flow turbines in shallow waters may hamper economic potential. In contrast, the power density and scalability of cross-flow turbines would suggest than an efficient design of either vertical or horizontal orientation is likely to have good economic potential. Ducted turbines, due to their more limited scalability and lower total power density, are likely to generate less power over the course of their lifespans, and therefore less of a return on investment.

Given their scalability in shallow waters, an efficient oscillating hydrofoil device is also likely to have good economic potential, comparable to that of a cross-flow turbine. Tidal kites, however, given their apparent requirement for deep waters, would not be capable of generating as much electricity, and consequently their economic potential is likely to be lower.

The comparatively large amount of materials and construction work required to construct a barrage, which by definition is even greater for a lagoon, means that the initial capital required for a range scheme will likely be significantly higher than it is for a tidal stream device. If a given amount of electricity is to be generated, this would signifi- 
cantly hamper the economic potential of a range scheme in comparison, at least at small scales. The longer lifespan of range devices (120 years with turbine replacement occurring every 40 years, in comparison to the 20 years for the MCT SeaGen) would go towards mitigating this, however. Whether it does so completely would depend upon the specifics of a project.

\subsubsection{Environmental impacts}

Given the similarities in how they extract energy from the flow, the environmental impacts of axial-flow and cross-flow turbines of both orientations are likely to be broadly the same. As discussed in Sect. 2.1.1, these will include impacts on water quality, such as reducing upstream and downstream flow speeds, potentially affecting sediment transport, and also accelerating the flow immediately around the device, potentially leading to scouring. Other risks include altering the habitats of benthic organisms, noise pollution, the generation of electromagnetic fields and the striking of marine animals with rotor blades or other moving parts. For ducted devices, it is possible that the higher drag coefficient caused by the extra structure of the duct may result in greater impacts on water quality, given that it has a greater impact on basin efficiency. The magnitude of the environmental impacts of an oscillating hydrofoil will likely be similar to those as well, though the potential for hydraulic fluids to leak into the environment will perhaps be a greater concern.

The small turbines of tidal kites would produce small wakes located higher in the water column, while the lack of a large superstructure would likely reduce scouring effects on the seabed compared with conventional axial-flow turbines. Depending on the range and speed of motion, however, tidal kites could present a greater danger of colliding with marine animals in comparison with static technologies. This may also result in a need for slightly larger exclusion zones around the device, to prevent collisions with marine traffic.

As discussed in Sect. 2.4, the environmental impacts of tidal range schemes can be positive as well as negative. For example, barrages may have uses in certain areas as flood defence schemes; however, changes in water level can adversely affect intertidal habitats, while the presence of large offshore structures also impacts sediment transport and the routes of migratory fish. From the literature, the regional impacts of barrages tend to be more significant than those of lagoons; however, lagoons may suffer more with recirculation currents within their basins due to their shape. Lagoons may also have more significant environmental impacts on the area directly surrounding them, particularly with regards to sediment transport and deposition. These impacts all tend to be proportional to the size of the scheme, and consequently will be significantly reduced at smaller scales. The generation scheme used, either ebb, flood, or two way, will also impact upon their magnitude; however, further research is required for these differences in impact to be assessed with certainty, due to a lack of empirical data. This is equally true of all tidal technologies.

\subsubsection{Overall suitability}

From the above discussion, tidal kites do not appear suitable for use in shallow water areas simply because they require deep waters to function correctly. Barrages and lagoons also appear unsuitable for small-scale generation, since they would require greater financial and material investment to install in comparison to a tidal stream device. Of the two, a lagoon would suffer more in terms of investment, while a barrage is likely to have greater impacts on the regional environment.

Ducted turbines do not appear as well suited as other technologies either. While their rotors have higher power densities than those of axial turbines, the additional area required for the duct means the total device power density is likely to be lower in practice. This additional structure also impedes the overall scalability of a device, which combined with lower overall power density would hamper economic potential. Axial-flow turbines also do not appear to be as suitable as some other technologies. Although they have higher power densities than the majority of the other concepts, their size is completely limited by depth, limiting the overall power output of a single device.

Oscillating hydrofoils have been described as being suitable for shallow water use (Kinsey et al. 2011; Pulse Tidal 2014), and certainly appear more suitable for shallow water applications than axial turbines. Although the mothballed Stingray device struggled with poor efficiency, the device tested by Kinsey et al. (2011) has a comparable efficiency to unducted turbines. This combined with their rectangular swept area means overall power output would not be constrained by depth, giving them good economic potential.

Both vertically and horizontally oriented cross-flow turbines appear to be very suitable for shallow water applications, due to their scalability and relatively high power densities. This means they should have greater generating capacity in shallow waters compared with axial-flow turbines, and consequently good economic potential. A vertical-axis configuration would be capable of operating in any flow direction, while the bi-directionality of a horizontally configured device would cope with ebb and spring tidal flows without the need for a yawing mechanism. The use of helical blades would also prevent the need for mechanically complex pitch-control systems. 


\section{Conclusions}

The suitability of eight different tidal power technologies for small-scale power generation in shallow near-shore waters off have been discussed by examining device performances in a number of key criteria. Our discussion suggests that both vertically and horizontally oriented cross-flow turbines appear to be well suited to this application, since they have relatively high power densities and a maximum device size that is unconstrained by depth. Oscillating hydrofoils also appear suitable to shallow water applications for similar reasons, provided comparable levels of efficiency can be reached. Meanwhile tidal kites, which require deep waters, and tidal barrages and lagoons, which will require significantly more investment to generate comparable levels of power at small-scale in comparison to turbines, appear to be the least appropriate for this scenario.

It is important to note that this examination is a simple design-stage assessment. Due to the developing nature of the tidal energy sector, several of the assessment criteria (e.g. environmental impacts, economic potential) are qualitative in nature and have been discussed in the absence of large amounts of reliable data. Additionally, given the influence various device-specific factors (e.g. hydrofoil blade profile) may have on device performance, certain comments may not apply to every device within a given technology class.

Although we have provided a general technology review for one type of tidal energy deployment in the absence of large amounts of field data, for a given project at a specific site there will be further complicating factors that will affect the performance of a given technology (e.g. blockage). The influences of these factors on performance may vary even throughout the site itself, and consequently as much data on the site as possible should be gathered before attempting to identify the most appropriate technology for that area.

Despite the eight discussed concepts appearing to comprise the bulk of tidal technology currently in development, there are also other devices used for micro hydropower applications, such as Archimedes screws and gravitational water vortices, which have not been investigated and could be suitable for use in shallow water tidal applications. Furthermore, it is possible that with suitable adaptation the ideas behind some of the concepts (the tidal kite for instance) could prove very effective for shallow water generation, while there is also scope that completely novel ideas could also be suitable. Consequently this discussion is by no means exhaustive or definitive. Future work will look to explore the possibilities of adapting both the discussed technologies and others to develop an optimised device for shallow water tidal power applications.
Acknowledgments The authors would like to thank Bournemouth University and the Balmain Environmental Trust for funding the project that this review is part of.

Open Access This article is distributed under the terms of the Creative Commons Attribution 4.0 International License (http://creativecomm ons.org/licenses/by/4.0/), which permits unrestricted use, distribution, and reproduction in any medium, provided you give appropriate credit to the original author(s) and the source, provide a link to the Creative Commons license, and indicate if changes were made.

\section{References}

Ahmadian R, Falconer RA (2012) Assessment of array shape of tidal stream turbines on hydro-environmental impacts and power output. Renew Energy 44:318-327

Ahmadian R, Falconer RA, Bockelmann-Evans B (2012) Far-field modelling of the hydro-environmental impact of tidal stream turbines. Renew Energy 38(1):106-116

Ahmadian R, Falconer RA, Lin B (2010) Hydro-environmental modelling of proposed Severn barrage, UK. Proc ICE Energy 163:107117

Ahmadian R, Morris C, Falconer RA (2010) Hydro-environmental modelling of off-shore and coastally attached impoundments of the North Wales Coast. In: The First IAHR European Congress, Edinburgh

Ahmadian R, Olbert AI, Hartnett M, Falconer RA (2014) Sea level rise in the Severn Estuary and Bristol Channel and impacts of a Severn Barrage. Comput Geosci 66:94-105

Archer AW, Hubbard MS (2003) Highest tides of the world. In: Chan MA, Archer AW (eds) Extreme depositional environments: mega end members in Geologic Time. Geological Society of America Special Paper 370, chap 9, pp 151-174

Bae YH, Kim KO, Choi BH (2010) Lake Sihwa tidal power plant project. Ocean Eng 37(5-6):454-463

Bahaj AS (2011) Generating electricity from the oceans. Renew Sustain Energy Rev 5(7):3399-3416

Bahaj AS, Molland AF, Chaplin JR, Batten WMJ (2008) Power and thrust measurements of marine current turbines under various hydrodynamic flow conditions in a cavitation tunnel and towing tank. Renew Energy 32(3):407-426

Bahaj AS, Myers LE (2003) Fundamentals applicable to the utilisation of marine current turbines for energy production. Renew Energy 28:2205-2211

Baker JR (1983) Features to aid or enable self-starting of fixed pitch low solidity vertical axis wind turbines. J Wind Eng Ind Aerodyn 15(1-3):369-390

Baker C, Walbancke J, Leache P (2006) Tidal lagoon power generation scheme in Swansea Bay. Welsh Development Agency, Department of Trade and Industry. http://www.bright-sparks.biz/wp-content/ uploads/2015/12/DTI-paper-on-Swansea-Bay-lagoon-scheme. pdf

Batten WMJ, Bahaj AS, Molland AF, Chaplin JR (2006) Hydrodynamics of marine current turbines. Renew Energy 31(2):249-256

Belloni C (2013) Hydrodynamics of ducted and open-centre tidal turbines PhD Thesis. University of Oxford

Betz A (1966) Introduction to the theory of flow machines. Pergamon Press, New York

Blunden LS, Bahaj AS (2006) Initial evaluation of tidal stream energy resources at Portland Bill. UK. Renew Energy 31(2):121-132

Bourne Energy (2014) Energy for the future. http://www.bourneenergy. com/future.html. Accessed 8 Apr 2014 
Bryden IG, Couch SJ, Owen A, Melville G (2007) Tidal current resource assessment. Proc Inst Mech Eng Part A J Power Energy 212(2):125-135

Bryden IG, Naik S, Fraenkel PL, Bullen CR (1998) Matching tidal current plants to local flow conditions. Energy 23(9):699-709

Charlier RH (2007) Forty candles for the Rance River TPP tides provide renewableand sustainable power generation. Renew Sustain Energy Rev 11(9):2032-2057

Clean Current Power Systems Inc (2012) Clean current-tidal in-stream turbines [Online]

Coiro DP, De Marco A, Nicolosi F, Melone S, Montella F (2005) Dynamic behaviour of the patented kobold tidal current turbine: numerical and experimental aspects. Acta Polytech 45(3):77-84

Coiro DP, Maisto U, Scherillo F, Melone S, Grasso F (2006) Horizontal axis tidal current turbine: numerical and experimental investigations. In: Proceeding of offshore wind and other marine renewable energies in Mediterranean and European seas, European seminar, Rome

Consul CA, Willden RHJ, Ferrer E, McColloch MD (2009) Influence of solidity on the performance of a cross-flow turbine. In: 8th European wave and tidal energy conference, Uppsala

Crown Estate (2012) UK Wave and Tidal Key Resource Areas Project: Summary Report. http://www.thecrownestate.co.uk/media/5476/ uk-wave-andtidal-key-resource-areas-project.pdf. Accessed 3 Mar 2016

Crown Estate (2013) UK Wave and Tidal Key Resource Areas Project: Technical Methodology Report. http://www. thecrownestate.co.uk/media/5478/uk-wave-and-tidal-keyresource-areastechnological-report.pdf. Accessed 3 Mar 2016

de Alegría IM, Martín JL, Kortabarria I, Andreu J, Ereño PI (2009) Transmission alternatives for offshore electrical power. Renew Sustain Energy Rev 13(5):1027-1038

Denny E (2009) The economics of tidal energy. Energy Policy 35(5):1914-1924

Department of Energy and Climate Change (2010) Strategic environmental assessment of proposals for tidal power development in the Severn Estuary: options definition report https://www.gov. uk/government/uploads/system/uploads/attachment_data/file/ 50260/3._Options_Definition_Report_Vol_1.pdf

Douglas CA, Harrison GP, Chick JP (2008) Life cycle assessment of the Seagen marine current turbine. Proc Inst Mech Eng Part M J Eng Marit Environ 222(1):1-12

Entec UK Ltd (2007) Tidal technologies overview. http://www. sdcommission.org.uk/data/files/publications/TidalPowerUK2Tidal_technologies_overview.pdf

Eriksson S, Bernhoff H, Leijon M (2008) Evaluation of different turbine concepts for wind power. Renew Sustain Energy Rev 12(5):1419_ 1434

European Marine Energy Centre (2014a) Tidal developers. http:// www.emec.org.uk/marine-energy/tidal-developers/. Accessed 3 Apr 2014

European Marine Energy Centre (2014b) Atlantis resources corporation. http://www.emec.org.uk/about-us/our-tidal-clients/atlantisresources-corporation-2/. Accessed 8 Apr 2014

European Parliament and Council of the European Union (2009) Directive 2009/28/EC of the European Parliament and and of the Council of 23 April 2009. On the promotion of the use of energy from renewable sources and amending and subsequently repealing Directives 2001/77/EC and 2003/30/EC. Off J Eur Union $16: 16-62$

Evans Engineering \& Power Company (2011) Severn tidal power reef http://severntidal.com/pdfs/EvansTidalPowerReefJan2011.pdf. Accessed 30 Oct 2015
Fairley I, Ahmadian R, Falconer RA, Willis MR, Masters I (2014) The effects of a Severn Barrage on wave conditions in the Bristol Channel. Renew Energy 68:428-442

Fairley I, Evans P, Wooldridge C, Willis M, Masters I (2013) Evaluation of tidal stream resource in a potential array area via direct measurements. Renew Energy 57:70-78

Fraenkel PL (2002) Power from marine currents. Proc Inst Mech Eng Part A J Power Energy 216(1):1-14

Fraenkel PL (2006) Tidal current energy technologies. Ibis 148(s1):145-151

Frau JP (1993) Tidal energy: promising projects: La Rance, a successful industrical-scale experiment. IEEE Trans Energy Convers 8(3):552-558

Frid C, Andonegi E, Depestele J, Judd A, Rihan D, Rogers SI, Kenchington $E$ (2012) The environmental interactions of tidal and wave enegy generation devices. Environ Impact Assess Rev 32(1):133139

Gaden DL, Bibeau E (2010) A numerical investigation into the effect of diffusers on the performance of hydro kinetic turbines using a validated momentum source turbine model. Renew Energy 35(6):1152-1158

Garrett C, Cummins P (2004) Generating power from tidal currents. J Waterw Port Coast Ocean Eng 130(3):114-118

Garrett C, Cummins P (2007) The efficiency of a turbine in a tidal channel. J Fluid Mech 588:243-251

Gill AB (2005) Offshore renewable energy: ecological implications of generating electricity in the coastal zone. J Appl Ecol 42:605-615

Gorban AN, Gorlov AM, Silantyev VM (2001) Limits of the turbine efficiency for free fluid flow. J Energy Resour Technol 123(4):311317

Hau E, von Renouard H (2013) Wind turbines: fundamentals, technologies, application, economics, 3rd edn. Springer, Berlin

HM Government (2008) Climate change act 2008. http://www.legis lation.gov.uk/ukpga/2008/27/contents

HM Government (2009) The UK low carbon transition plan: national strategy for climate and energy. https://www.gov.uk/ government/uploads/system/uploads/attachment_data/file/22875 2/9780108508394.pdf

HM Government (2011) The carbon plan: delivering our low carbon future. https://www.gov.uk/government/uploads/sys tem/uploads/attachment_data/file/47613/3702-the-carbon-plandelivering-our-low-carbon-future.pdf

HM Government (2015) Commercial negotiations to start on Swansea Bay Tidal Lagoon. https://www.gov.uk/government/ news/commercial-negotiations-to-start-on-swansea-bay-tidal-lag oon. Accessed 19 March 2015

House of Commons Energy and Climate Change Comittee (2013) A Severn Barrage? Second report of session 2013-14: volume 1. http://www.publications.parliament.uk/pa/cm201314/ cmselect/cmenergy/194/194.pdf

Howell R, Qin N, Edwards J, Durrani N (2010) Wind tunnel and numerical study of a small vertical axis wind turbine. Renew Energy 35(2):412-422

Kadiri M, Ahmadian R, Bockelmann-Evans B, Rau W, Falconer R (2012) A review of the potential water quality impacts of tidal renewable energy systems. Renew Sustain Energy Rev 16(1):329341

Kadlec EG (1978) Characteristics of future vertical-axis wind turbines. Sandia National Laboratories. http://prod.sandia.gov/ techlib/accesscontrol.cgi/1979/791068.pdf

Kelly KA, McManus MC, Hammond GP (2012) An energy and carbon life cycle assessment of tidal power case study: the proposed Cardiff-Weston severn barrage scheme. Energy 44(1):692-701 
Kim G, Lee ME, Lee KS, Park JS, Jeong WM, Kang SK, Soh JG, Kim $H$ (2012) An overview of ocean renewable energy resources in Korea. Renew Sustain Energy Rev 16(4):2278-2288

Kinsey T, Dumas G, Lalande G, Méhut A, Viarouge P, Lemay J, Jean Y (2011) Prototype testing of a hydrokinetic turbine based on oscillating hydrofoils. Renew Energy 36(6):1710-1718

Kirby R, Shaw TL (2005) Severn Barrage, UK-environmental reappraisal. Proc ICE Eng Sustain 158(1):31-39

Kirke BK, Lazauskas L (2008) Variable pitch Darrieus water turbines. J Fluid Sci Technol 3(3):430-438

Kirke BK, Lazauskas L (2011) Limitations of fixed pitch Darrieus hydrokinetic turbines and the challenge of variable pitch. Renew Energy 36(3):893-897

Kyozuka Y (2008) An experimental study on the Darrieus-Savonius turbine for the tidal current power generation. J Fluid Sci Technol 3(3):439-449

Lamb H (1994) Hydrodynamics, 6th edn. Cambridge University Press, Cambridge

Lanchester FW (1915) A contribution to the theory of propulsion and the screw propeller. J Am Soc Naval Eng 27(2):509-510

Lebarbier CH (1975) Power from tides-the Rance Tidal Power Station. Naval Eng J 87:57-71

McAdam R, Holsby G, Oldfield M, McColloch M (2010) Experimental testing of the transverse horizontal axis water turbine. IET Renew Power Gener 4(6):510-518

MCT Ltd (2014) SeaGen S [Online]. http://www.marineturbines.com/ SeaGen-Products/SeaGen-S. Accessed 8 Apr 2014

Minesto (2013) Deep green technology. http://www.minesto.com/ deepgreentechnology/. Accessed 3 Mar 2014

Minesto (2014) Deep green technical data. Renewable UK Wave and Tidal 2014, Belfast

Myers LE, Bahaj AS (2006) Power output performance characteristics of a horizontal axis marine current turbine. Renew Energy 31(2):197-208

Neill SP, Litt EJ, Couch SJ, Davies AG (2009) The impact of tidal stream turbines on large-scale sediment dynamics. Renew Energy 34(12):2803-2812

Newman BG (1983) Actuator-disk theory for vertical-axis wind turbines. J Wind Eng Ind Aerodyn 15(1-3):347-355

Newman BG (1986) Multiple actuator- disc theory for wind turbines. J Wind Eng Ind Aerodyn 24(3):215-225

O’Doherty T, Mason-Jones A, O'Doherty DM, Byrne CB (2009) Experimental and computational analysis of a model horizontal axis tidal turbine. In: 8th European wave and tidal energy conference, Uppsala

Polagye B, Copping A, Kirkendall K, Boehlert G, Walker S, Wainstein M, Cleve BV (2010) Environmental effects of tidal energy development: a scientific workshop. University of Washington, Seattle, Workshop Briefing Paper

Premalatha M, Abbasi T, Abbasi SA (2014) Wind energy: increasing deployment, rising environmental concerns. Renew Sustain Energy Rev 31:270-288

Pulse Tidal (2014) Our technology: overview [Online]. http://pulsetidal. com/our-technology.html. Accessed 3 Mar 2014

Roh SC, Kang SH (2013) Effects of a blade profile, the Reynolds number, and the solidity on the perferomance of a straight bladed vertical axis wind turbine. J Mech Sci Technol 27(11):3299-3307

Rourke FO, Boyle F, Reynolds A (2010a) Tidal energy update 2009. Appl Energy 87(2):398-409

Rourke FO, Boyle F, Reynolds A (2010b) Marine current energy devices: current status and possible future applications in Ireland. Renew Sustain Energy Rev 14(3):1026-1036
Shields MA, Woolf DK, Grist EPM, Kerr SA, Jackson AC, Harris RE, Bell MC, Beharie R, Want A, Osalusi E, Gibb SW, Side J (2011) Marine renewable energy: the ecological implications of altering the hydrodynamics of the marine environment. Ocean Coast Manag 51(1):2-9

Shiono M, Suzuki K, Kiho S (2000) An experimental study of the characteristics of a Darrieus turbine for tidal power generation. Electr Eng Jpn 132(3):781-787

Shives M, Crawford C (2010) Overall efficiency of ducted tidal current turbies. In: OCEANS 2010:1-6, Seattle, Washington

Sustainable Development Commision (2007) Turning the tide: tidal power in the UK. http://www.sdcommission.org.uk/data/files/ publications/Tidal_Power_in_the_UK_Oct07.pdf

The Engineering Business Ltd (2003) Stingray tidal stream energy device-phase 2. Department of Trade and Industry. https://archive. uea.ac.uk/e680/energy/energy_links/renewables/stingray_part1. pdf

The Engineering Business Ltd (2005) Stingray tidal stream energy device-phase 3. Department of Trade and Industry. https://tethys. pnnl.gov/sites/default/files/publications/Stingray_Tidal_Stream_ Energy_Device.pdf

Tidal Energy Pty Ltd (2015) Tidal Energy Pty Ltd website. http:// tidalenergy.com.au/faq.html. Accessed 29 Oct 2015

Tidal Lagoon Swansea Bay PLC (2015) Lagoon map. http://www. tidallagoonswanseabay.com/assets/images/lagoon_map.jpg. Accessed 19 March 2015

University of Strathclyde (2006) Technology: oscillating hydrofoil. http://www.esru.strath.ac.uk/EandE/Web_sites/05-06/marine_ renewables/technology/oschydro.htm. Accessed 3 Mar 2014

Vennell R (2012) The energetics of large tidal turbine arrays. Renew Energy 48:210-219

Voith Hydropower (2014) Tidal current power stations. http://www. voith.com/en/products-services/hydro-power/ocean-energies/tid al-current-power-stations-591.html. Accessed 8 Apr 2014

Walker JM, Flack KA, Lust EE, Schultz MP, Luznik L (2014) Experimental and numerical studies of blade roughness and fouling on marine current turbine performance. Renew Energy 66:257-267

Whelan JI, Graham MR, Peiró J (2009) A free-surface and blockage correction for tidal turbines. J Fluid Mech 624:281-291

Wikipedia.org (2015) Rance Tidal Power Station. http://en.wikipedia. org/wiki/Rance_Tidal_Power_Station. Accessed 19 Mar 2015

Wyre Tidal Energy (2014) How a barrage works. http://www. wyretidalenergy.com/tidal-barrage/how-a-barrage-works. Accessed 19 Mar 2014

Xia J, Falconer R, Lin B (2010a) Impact of different operating modes for a Severn Barrage on tidal power and flood inundation in the Severn Estuary. UK. Appl Energy 87(7):2374-2391

Xia JQ, Falconer RA, Lin B (2010b) Impact of different tidal renewable energy projects on the hydrodynamic processes in the Severn Estuary, UK. Ocean Modelling 32:86-104

Xia J, Falconer RA, Lin B (2010c) Hydrodynamic impact of a tidal barrage in the Severn Estuary. UK. Renew Energy 35(7):14551468

Xia J, Falconer RA, Lin B, Tan G (2012) Estimation of annual energy output from a tidal barrage using two different methods. Appl Energy 93:327-336

Yang B, Shu XW (2012) Hydrofoil optimization and experimental validation in helical vertical axis turbine for power generation from marine current. Ocean Eng 42:35-46

Zhou J, Falconer RA, Lin B (2014) Refinements to the EFDC model for predicting the hydro-environmental impacts of a barrage across the Severn Estuary. Renew Energy 62:490-505 